Association for Information Systems AIS Electronic Library (AISeL)

AMCIS 2003 Proceedings

Americas Conference on Information Systems

(AMCIS)

December 2003

\title{
A Study on Tolerable Waiting Time: How Long Are Web Users Willing to Wait?
}

Fiona Nah

University of Nebraska, Lincoln

Follow this and additional works at: http://aisel.aisnet.org/amcis2003

\section{Recommended Citation}

Nah, Fiona, "A Study on Tolerable Waiting Time: How Long Are Web Users Willing to Wait?" (2003). AMCIS 2003 Proceedings. 285.

http://aisel.aisnet.org/amcis2003/285

This material is brought to you by the Americas Conference on Information Systems (AMCIS) at AIS Electronic Library (AISeL). It has been accepted for inclusion in AMCIS 2003 Proceedings by an authorized administrator of AIS Electronic Library (AISeL). For more information, please contact elibrary@aisnet.org. 


\title{
A Study on Tolerable Waiting Time: HoW Long ARE Web USERS Willing to Wait?
}

\author{
Fiona Fui-Hoon Nah \\ University of Nebraska, Lincoln \\ fnah@unl.edu
}

\begin{abstract}
The $W W W$ has become an important channel for information access, electronic commerce, and publication. With an exponential increase in the number of Web users and the popularity of multimedia technology, users often face a long waiting time for downloading Web pages. Although various technologies and techniques have been implemented to alleviate the situation and to comfort the impatient users, little research has been done to assess what constitutes an acceptable and tolerable waiting time for Web users. This research reviews the literature on computer response time and users' waiting time, and assesses Web users' tolerable waiting time in information retrieval. It addresses the following question through an empirical study: How long are users willing to wait for a Web page to be downloaded before abandoning it? The results from this study suggest that the tolerable waiting time for information retrieval is approximately 2 seconds.
\end{abstract}

Keywords: WWW, tolerable waiting time, computer response time

\section{Introduction}

The World Wide Web (WWW) has become an important channel for information retrieval, electronic commerce, and entertainment. However, long Web page download times have remained a major cause of frustration among Web users (Selvidge, 1999, 2003). According to the findings of the surveys conducted by Lightner, Bose \& Salvendy (1996) and the GVU (Graphic, Visualization, \& Usability) Center at the Georgia Institute of Technology (GVU, October 1998), long download times have always been a major problem experienced by WWW users. The survey by Pitkow and Kehoe (1996) also indicates that the most widely cited problem with using the Web was that it took too long to download Web pages (i.e., $69 \%$ of respondents cited this problem). This problem is so noticeable that WWW users often equate the "WWW" acronym with "World Wide Wait"!

The WWW has become an important and popular information search tool. It provides convenient access to almost all kinds of information - from education to entertainment. It also makes global information available at our fingertips. Although the WWW is now accessible from mobile devices, usage and adoption rates are low due to the long download time and limited bandwidth available in the wireless environment. As noted earlier, long waiting time for downloading Web pages is often not tolerable even in the wired environment. This situation is worsened by the increasing and excessive use of multimedia data (i.e., audio and video clips) on Web pages. This problem of 'long download time' is relevant not only to WWW users but also to the authors and designers of websites - as websites that take a long time to download are rarely or less frequently visited (Reaux and Carroll, 1997). Hence, it is important for us to gain a more in-depth understanding of Web users' waiting behavior. More specifically, the question of interest is: how long are users willing to wait for downloading a Web page before abandoning it? We will refer to this duration as the 'tolerable waiting time' for Web users.

The answer to the above research question is important for making decisions on hardware and software investments as well as Web page design and contents in order to provide acceptable download time to users. Network providers and website designers make such decisions based on their understanding of what constitutes an acceptable download time. Since the types of task (e.g., information retrieval, browsing, purchasing, downloading of files) may have an impact on users' level of tolerance, we will examine information retrieval task in this research, which is one of the most common tasks on the WWW. 
The rest of this paper is organized as follows: The next section reviews the literature on users' waiting time and presents the hypothesized tolerable waiting times as proposed in the literature. Section 3 describes an experimental study that was carried out to determine Web users' tolerable waiting time for information retrieval. The results of the study are reported in Section 4. Section 5 concludes with research implications and discussions for future research.

\section{Literature on Waiting Time}

According to Nielsen (1999), download speeds are the "single-most important design criterion on the Web" (p.67). Although long download time of Web pages has been a consistent problem encountered by Web users (Lightner et al., 1996; Pitkow and Kehoe, 1996; Selvidge, 1999, 2003), it is still controversial as to what constitutes an acceptable waiting time for a typical Web page download. Nielsen (1997) advocates the 10-second limit, while Zona Research (1999) recommends the 8-second rule. Selvidge's $(1999,2003)$ study indicates that there is no difference in users' frustration levels between 1 -second and 20 -second delay, but a difference (with 1-second delay) was observed at 30-second delay. Other researchers propose the 2-second rule (Shneiderman, 1984 ) and the 12-second rule (Hoxmeier \& DiCesare, 2000). The conflicting evidence in the literature was also highlighted and examined by Galletta, Henry, McCoy \& Polak (2002), who observed decreases in performance and behavioral intentions at 4 seconds. Interestingly and ironically, the average American users that use dial-up connections wait about 30 seconds the first time they look at a new Web page (Chen, 2002)!

Web page download time is affected by the performance of the browser, the speed of the Internet connection, the local network traffic, the load on the remote host, and the structure and format of the Web page requested. In this research, we are not addressing the issue of how these different variables can be balanced or traded-off to produce an acceptable download time, but rather we are interested in finding out what constitutes an acceptable or, more exactly, tolerable download time for typical Web users.

\section{Computer Response Time}

This section reviews earlier research on computer response times where it is suggested that (Miller, 1968; Nielsen, 1993):

(1) 0.1 second is about the limit for having the user feel that the system is reacting instantaneously, meaning that no special feedback is necessary except to display the result.

(2) 1.0 second is about the limit for the user's flow of thought to stay uninterrupted, even though the user will notice the delay. Normally, no special feedback is necessary during delays of more than 0.1 but less than 1.0 second, but the user does lose the feeling of operating directly on the data.

(3) 10 seconds is about the limit for keeping the user's attention focused on the dialogue. For longer delays, users will want to perform other tasks while waiting for the computer to finish, so they should be given feedback indicating when the computer expects to be done.

Even though traditional human factor guidelines suggest that 10 seconds is the maximum response time before computer users lose interest (Miller, 1968; Nielsen, 1993, 1997), 15 seconds is considered tolerable (Nielsen, 1995, 1996). According to Nielsen (1995), Web users have been "trained to endure so much suffering that it may be acceptable to increase the limit value to 15 seconds". Shneiderman (1984), on the other hand, recommends that the computer should respond to users within two seconds. For tasks where uninterrupted focus is critical, Nielsen (1995) suggests that the response should be kept within one second. So, what is a reasonable and acceptable waiting time for download of Web pages? Is it 1, 2, 10 or 15 seconds? Unfortunately, there is no clear empirical evidence that supports any of these "magic numbers". The question will need to be answered through empirical investigations.

Based on the above discussions, several (alternate) hypotheses are derived.

Nielsen made several proposals concerning download time. According to Nielsen $(1995,1996)$, Web users may be willing to tolerate up to 15 seconds for a download. Thus, according to him, the tolerable waiting time of web users is 15 seconds.

H1: The threshold for tolerable waiting time is 15 seconds. 
However, Nielsen's (1993) original proposal suggests that the threshold for Web users' tolerable waiting time is 10 seconds. This guideline has been widely cited and acknowledged by several researchers (e.g., Fry, 2001; Bailey, 2001). Hence, according to this guideline, the hypothesis would be as follows:

\section{H2: The threshold for tolerable waiting time is 10 seconds.}

Shneiderman (1984) reviewed the literature on computer response time and suggests that the 2-second limit seems most appropriate for many online tasks. For instance, he cited Youman's study where it was found that users' reactions were changed from predominantly acceptable to predominantly unacceptable around 2 seconds. Thus, based on Shneiderman's recommendation, it is hypothesized that:

\section{H3: The threshold for tolerable waiting time is 2 seconds.}

Nielsen (1993) has also indicated that computer response should be kept within one second if the users' focus on the task is critical or needs to be maintained. Although this recommendation may be more applicable for open browsing than for focused information retrieval task, it is included as a hypothesis below.

\section{H4: The threshold for tolerable waiting time is 1 second.}

\section{Tolerable Waiting Time}

The tolerable waiting time for downloading a Web page may depend on various factors such as level of experience and age of users, individual user's characteristics (i.e., propensity to wait), task type, expected content of the Web page, expected download time, and information available about the wait. Such variability and its associated research challenge should not deter us from studying the 'waiting time' phenomenon and Web users' waiting behavior. Although several studies have investigated the relationships between download time and users' perceptions and attitudes, empirical research that investigates actual waiting behavior of users is scarce (Selvidge, 2003). This research differs from earlier studies in that it focuses on understanding Web users' waiting behavior in order to determine Web users' tolerable waiting time.

Ramsey, Barbesi \& Preece (1998) found that page loading delays (from 2 seconds to 2 minutes) had strong effects on users' perceptions of websites. The results indicate that Web pages that were downloaded faster were perceived to be more interesting than the slower ones. Their results also suggest that 41 seconds is the cut-off for long delays. Since, according to their study, users began to perceive differences at this threshold, it is hypothesized that:

\section{H5: The threshold for tolerable waiting time is 41 seconds.}

Based on empirical studies carried out by Selvidge (1999,2003), a threshold of 30 seconds was suggested. No statistical difference was observed between the effects of one, 10- and 20-second delays and users' frustration levels. However, the effects of one, 30and 60-second delays produced significant differences in both performance and frustration levels. Thus, from Selvidge's study, it is deduced that:

\section{H6: The threshold for tolerable waiting time is 30 seconds.}

Hoxmeier \& DiCesare (2000) also examined the relationship between system response time (0, 3, 6, 9, 12 seconds) and several users' perception measures. The results show that satisfaction decreases with increases in response time. More importantly, their findings suggest that the level of intolerance occurs at the 12-second response range. Thus, according to their findings:

\section{H7: The threshold for tolerable waiting time is 12 seconds.}

Galletta et al. (2002) examined delay times of $0,2,4,6,8$, and 12 seconds using an experiment. Their findings suggest that, "decreases in performance and behavioral intentions begin to flatten when the delays extend to 4 seconds or longer, and attitudes flatten when the delays extend to 8 seconds or longer". Thus, according to them, the users' tolerable waiting time is around 4 seconds (since waiting behavior is more closely related to performance and behavioral intentions than attitudes). Therefore, their results suggest that: 
H8: The threshold for tolerable waiting time is 4 seconds.

Although other research works have been done to study delay times, due to the space constraint, we only included those that provide specific recommendations concerning tolerable waiting time of Web users. Our review of the literature indicates that a wide range (from 1 second to 41 seconds) of tolerable waiting time has been proposed. The following section describes an experimental study that was carried out to assess the tolerable waiting time of Web users.

\section{Research Model and Methodology}

Although users' tolerance on a Web page download may vary for different types of tasks (such as information retrieval, online purchasing, downloading of files), in this study, users' tolerable waiting time is studied in the context of purposeful browsing in information retrieval as opposed to open-browsing. Given that users' tolerable waiting time may be moderated by a number of factors, we controlled for task type (information retrieval), user characteristics (sophomore business major students who were savvy Web users), browser interface (specifically designed for the study), domain of information retrieval (information on software and hardware tools), and the specific Web pages that were accessed by users. Since the literature has suggested that feedback information about the wait and availability of graphics/pictures on the Web pages may affect users' tolerable waiting time (Dellaert and Kahn, 1999; Folkman, 1984; Hui and Zhou, 1996), we manipulated both of these variables using a 2 X2 experimental design. The research model is shown in Figure 1.

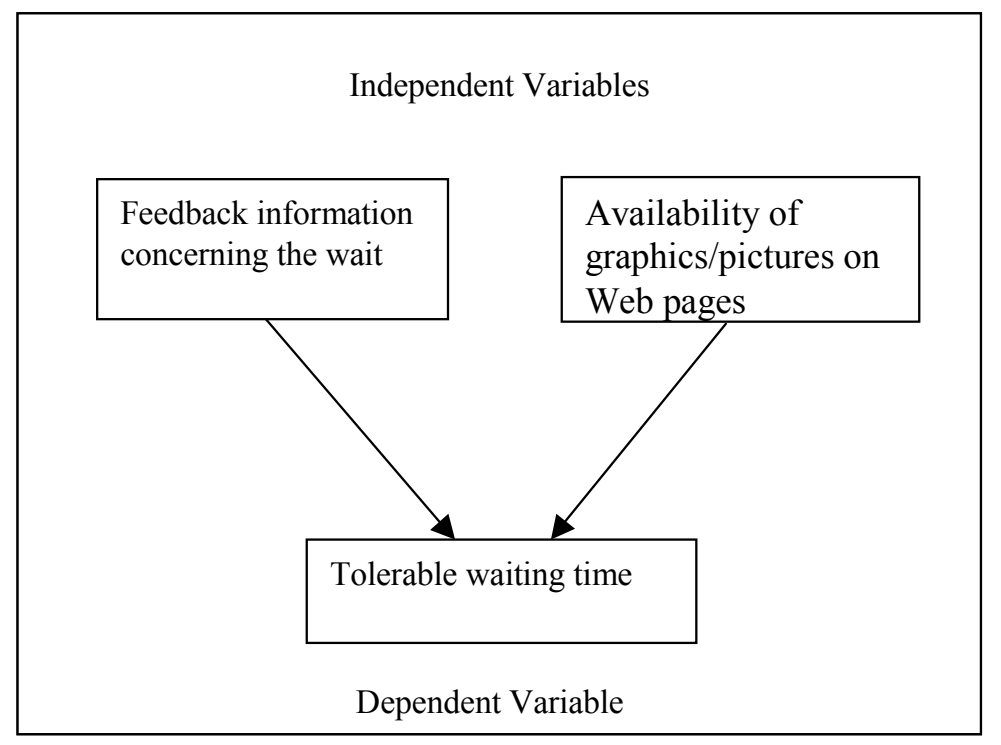

Figure 1. Research Model

Hence, the $2 \mathrm{X} 2$ experimental study produces the following four scenarios:

1. Provision of a feedback bar on the Web browser and access to Web pages that contain pictures in addition to textual information;

2. Provision of a feedback bar on the Web browser and access to Web pages that contain only textual information (without pictures);

3. No feedback bar available on the Web browser and access to Web pages that contain pictures in addition to textual information;

4. No feedback bar available on the Web browser and access to Web pages that contain only textual information (without pictures). 
The feedback bar on the browser was a moving bar that signified to the users that the system was carrying out their request. It provided indications that the system was in a 'working' mode. The bar moved in a bi-directional manner (left to right, right to left, left to right, and so on) until the user's request was satisfied (i.e., the Web page was downloaded). Note that the feedback bar did not provide waiting duration information or status of the download per se, but simply an indication that it was working.

The other treatment was the nature of information available on the Web pages. For the experiment, the subjects were requested to look up the names of software and hardware tools. One group of subjects was provided with both textual and pictorial information about the tools, while the other group was provided with textual information only. Both groups received exactly the same textual information, but the first group was also provided with pictures of the tools. The pictures were included to enhance the look of the Web pages by making the Web pages look more appealing and interesting.

Seventy subjects participated in the experiment. The subjects were undergraduate students enrolled in introductory MIS classes. They were randomly assigned into four groups for the experiment. The experiment was conducted as a laboratory assignment during class time. The subjects have completed the development of their class home pages and were savvy Web users. The subjects were provided with a list of questions and were required to access the Web pages to obtain the answers to the questions. All subjects used the same browser and interface (that was designed for the experiment). All of them received the same training session at the beginning of the experiment that familiarized them with the various buttons/icons available on the Web browser (specifically, the "STOP" button). All subjects began the browsing task from a standard Web page that was designed specifically for the experiment. This standard Web page provided hyperlinks to the other Web pages that contained the information needed to complete the assignment.

More specifically, the subjects were asked to look up the names of $10 \mathrm{Web}$ acceleration tools using the standard Web page provided to them. Of the 10 hyperlinks provided on the standard Web page, only 7 of them were working. Upon clicking on any of these 7 working hyperlinks, their corresponding Web page would appear instantaneously (i.e., with negligible download time). The fourth, seventh, and ninth hyperlinks triggered an infinite waiting time. For these 3 non-working hyperlinks, the subjects would have to click the "STOP" icon to terminate the wait. The users" tolerable waiting time (for the download of a Web page) is the elapsed time between the moment the hyperlink was clicked (i.e., download request was made) and the moment the "STOP" button was clicked (i.e., download request was terminated). The computer log captured the elapsed times and all mouse-click actions for subsequent data analysis.

\section{Research Findings}

The results of this study indicate that users' waiting time was not affected by the availability or unavailability of pictures on the Web pages. This is not surprising, as the pictures did not convey any additional information needed to complete the assignment. As such, we collapsed the data points across the two levels of this factor in subsequent analysis.

More interestingly, the inclusion of a feedback bar significantly prolonged the waiting time of users (see table 1). The average waiting time for the first access to a non-working hyperlink was 13 seconds for the control group (no feedback bar) and 38 seconds for the experimental group (with feedback bar). The mode (i.e., peak in frequency) for users' waiting time was analyzed using intervals of one second. The mode for the first access to a non-working hyperlink for the control or 'no feedback bar' condition fell within the intervals of 5-6, 6-7 and 7-8 seconds, with a frequency of 4 in each interval. Hence, $33 \%(4 \times 3 / 36)$ of the users terminated their first unsuccessful download request between 5-8 seconds. As for the 'feedback bar' condition, the mode occurred in various intervals between 15-46 seconds. The Mann-Whitney test indicates that the difference between the two treatment conditions (with and without feedback bar) for the first non-working hyperlink is highly significant (as shown in the table 1).

As subjects proceeded with the task, their waiting time for accessing non-working hyperlinks decreased. This was probably because after encountering one unsuccessful download, the subjects no longer expected all of the Web pages to be successfully downloaded. Hence, their expectations may have declined, causing their tolerable waiting time to decrease. The average waiting time for the first access to a second non-working hyperlink was 4 seconds for the control group (no feedback bar) and 17 seconds for the treatment group (with feedback bar). The Mann-Whitney test indicates that the difference is significant $(\mathrm{p}<.002)$. The mode for the control group was in the intervals of 2-3 and 3-4 seconds, with a frequency of 11 in each interval. Thus, $61 \%(11 \times 2 / 36)$ of the users in the control condition gave up their wait to access the second non-working hyperlink between 2-4 seconds. The mode for the treatment group occurred in the interval of 2-3 seconds, with a frequency of 9 . Thus, $26 \%(9 / 34)$ of the users in the treatment condition gave up their wait to access the second non-working hyperlink between the period of 2-3 seconds. 
Table 1. Statistics on Waiting Time for WWW Access

\begin{tabular}{|c|c|c|c|}
\hline & \multicolumn{3}{|c|}{$\begin{array}{l}\text { Subjects' Waiting Time for First Access to Non-Working Hyperlinks } \\
\end{array}$} \\
\hline & 1st non-working hyperlink & 2nd non-working hyperlink & 3rd non-working hyperlink \\
\hline $\begin{array}{l}\text { Control } \\
\text { (36 subjects) }\end{array}$ & $\begin{array}{l}\text { Mean }=13 \text { sec. } \\
\text { Median }=9 \text { sec. } \\
\text { Mode }=5-8 \text { sec. }\end{array}$ & $\begin{array}{c}\text { Mean }=4 \text { sec. } \\
\text { Median }=3.6 \text { sec. } \\
\text { Mode }=2-4 \text { sec. }\end{array}$ & $\begin{array}{c}\text { Mean }=3.3 \mathrm{sec} \\
\text { Median }=2.5 \mathrm{sec} . \\
\text { Mode }=2-3 \mathrm{sec}\end{array}$ \\
\hline $\begin{array}{l}\text { Treatment } \\
\text { (34 subjects) }\end{array}$ & $\begin{array}{c}\text { Mean }=37.6 \text { sec. } \\
\text { Median }=22.6 \text { sec. } \\
\text { Mode }=15-16,20-22,45-46 \\
\text { sec. }\end{array}$ & $\begin{array}{c}\text { Mean }=17 \text { sec. } \\
\text { Median }=8.4 \mathrm{sec} \\
\text { Mode }=2-3 \mathrm{sec}\end{array}$ & $\begin{array}{l}\text { Mean }=6.7 \text { sec } \\
\text { Median }=4.3 \mathrm{sec} \\
\text { Mode }=2-3 \mathrm{sec}\end{array}$ \\
\hline Mann-Whitney Test & $\mathrm{p}<.000$ & $\mathrm{p}<.002$ & $\mathrm{p}<.004$ \\
\hline
\end{tabular}

The average waiting time for the first access to the last non-working hyperlink encountered was 3 seconds for the control group (no feedback bar) and 7 seconds for the treatment group (with feedback bar). The Mann-Whitney test indicates that the difference is significant $(\mathrm{p}<.004)$. The mode for both groups was in the interval of $2-3$ seconds, with a frequency of $13(36 \%)$ for the control group and a frequency of $8(24 \%)$ for the treatment group. Thus, the majority of the users gave up the wait between $2-3$ seconds.

Overall, our results seem to support Hypothesis 3, which indicates that the tolerable waiting time is approximately 2 seconds. Shneiderman (1986) proposed the 2-second limit based on his review of the literature on computer response time and Miller's (1968) earlier work.

Figures 2 and 3 show the distributions of waiting time (in intervals of 5 seconds) for the first non-working hyperlink. Figures $4-7$ show the distributions of waiting times (in intervals of 5 seconds) for the other two non-working hyperlinks.

As shown in figures 2 and 3, the subjects' waiting time was significantly prolonged when a status bar was provided on the Web browser $(\mathrm{p}<.000$ - see table 1$)$. In the case where no status bar was provided, the mode for waiting time was between 5 - 10 seconds (when analyzed in 5-second interval), as shown in figure 2.

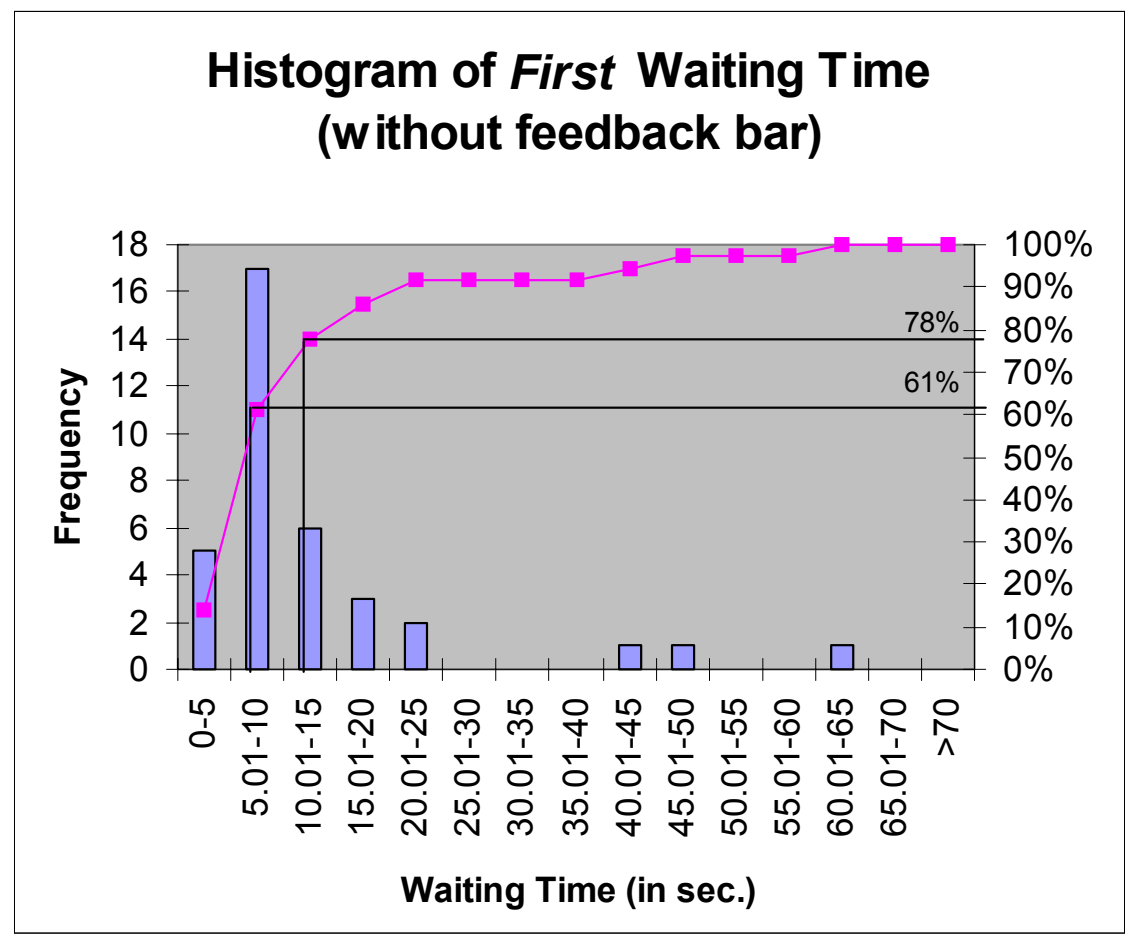

Figure 2. Cumulative Distribution of Waiting Time in the Absence of a Feedback Bar 


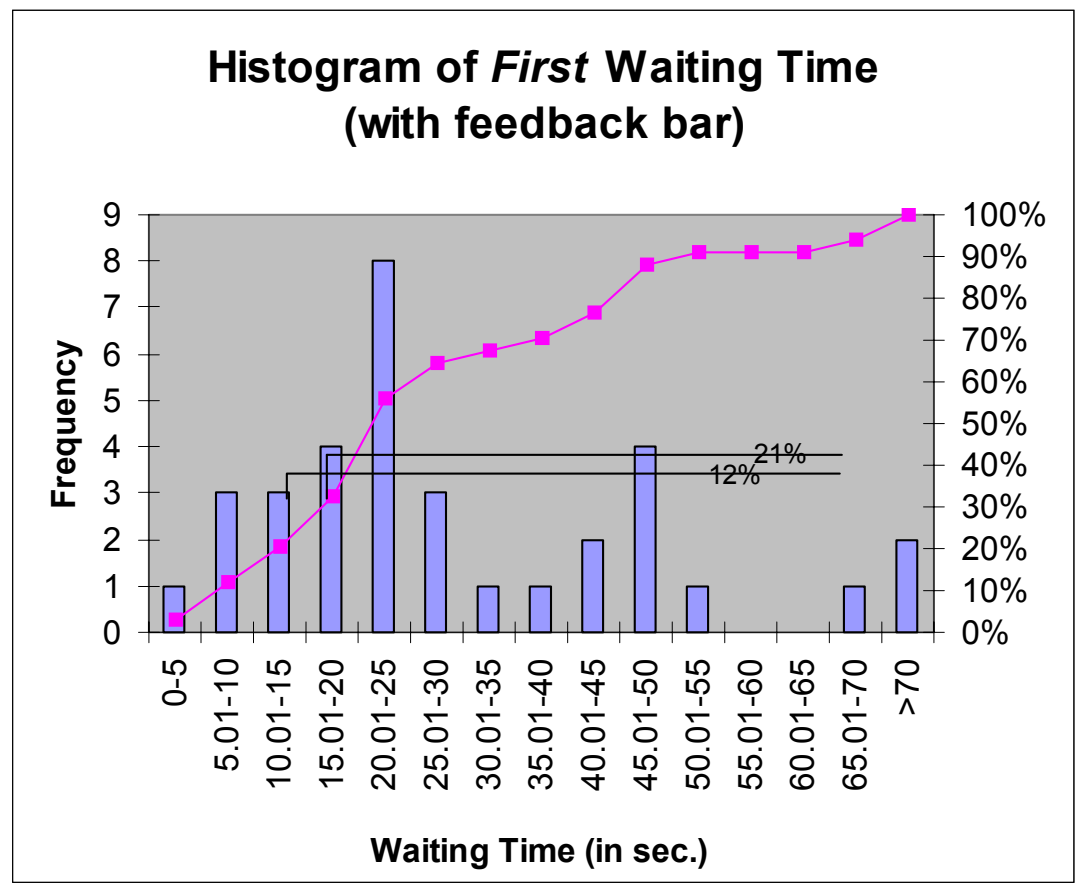

Figure 3. Cumulative Distribution of Waiting Time in the Presence of a Feedback Bar

As for the first accesses to the other two non-working hyperlinks, none of the users in the control setting (i.e., no status bar) waited more than 15 seconds, as shown in figures 4 and 5.

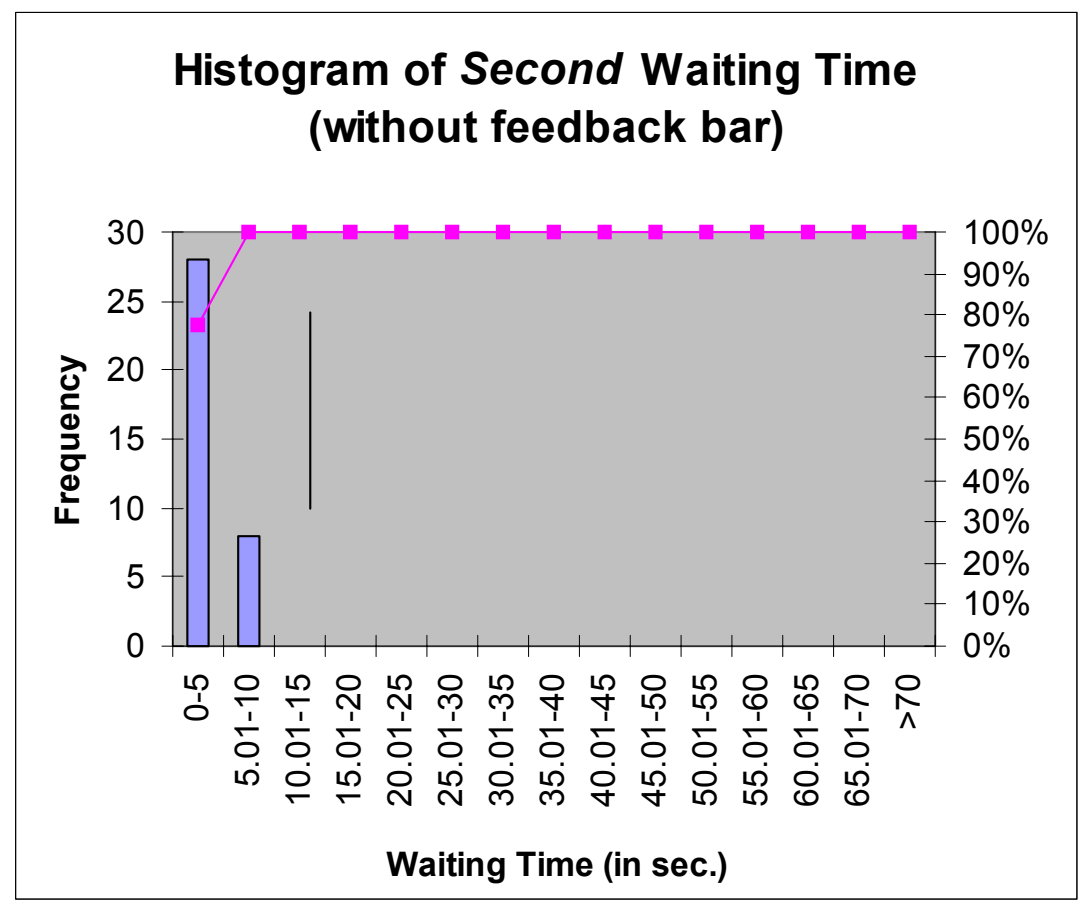

Figure 4. Cumulative Distribution of Waiting Time for First Access to a Second Non-Working Hyperlink in the Absence of a Feedback Bar 


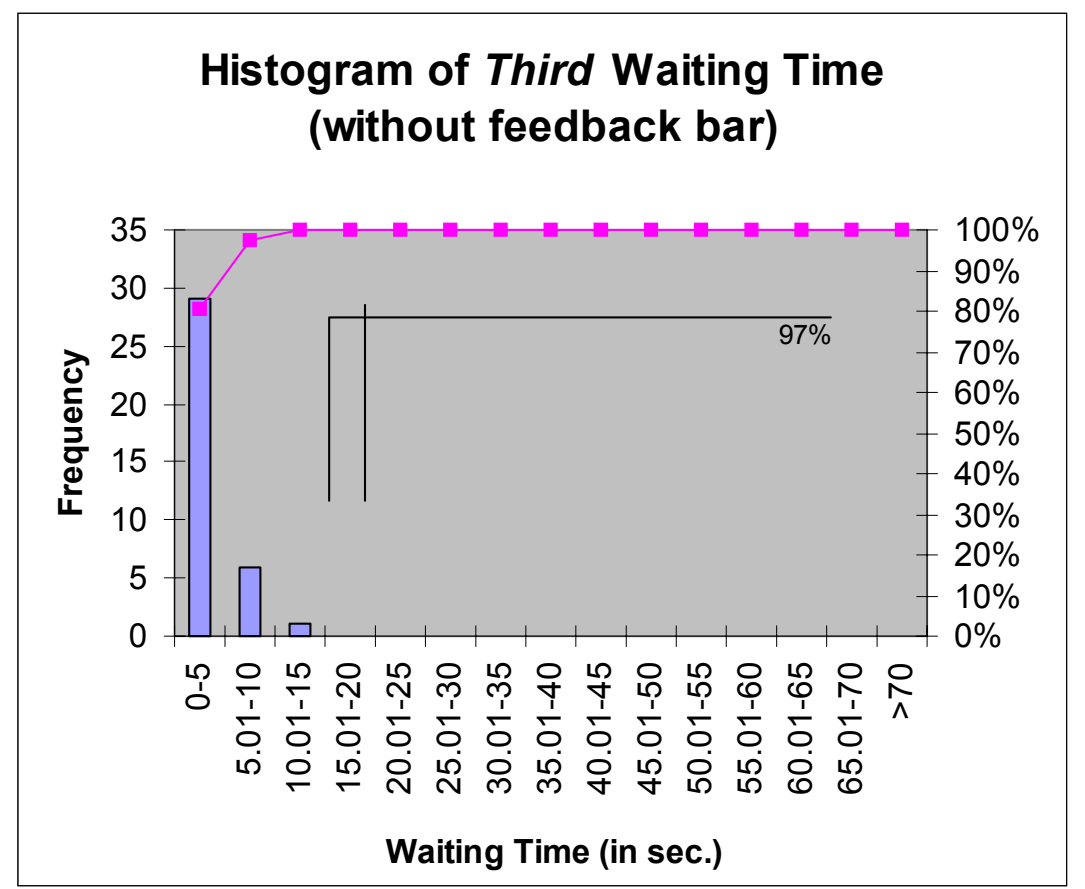

Figure 5. Cumulative Distribution of Waiting Time for First Access to the Final/Third Non-Working Hyperlink in the Absence of a Feedback Bar

However, the scenario was different when a status bar was provided (see figures 6 and 7). When a feedback bar was provided, users' tolerable waiting time increased.

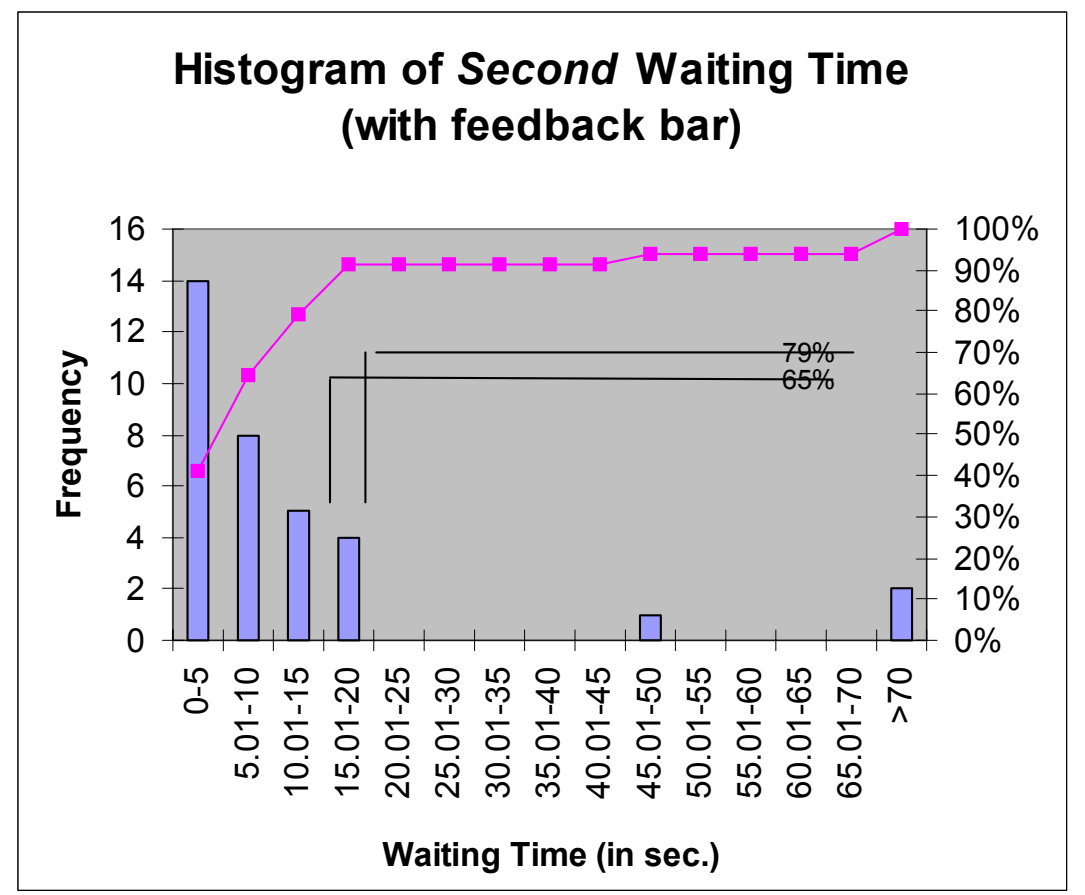

Figure 6. Cumulative Distribution of Waiting Time for First Access to a Second Non-Working Hyperlink in the Presence of a Feedback Bar 


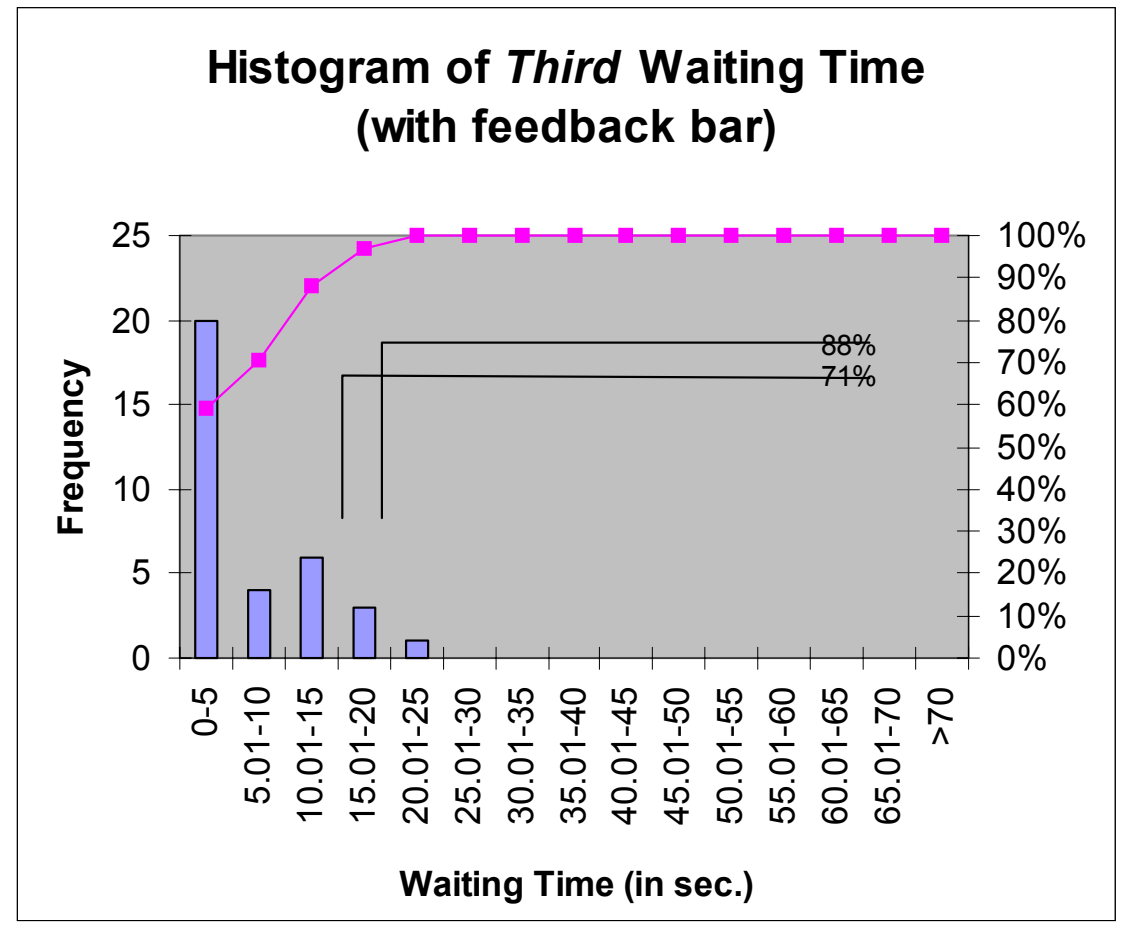

Figure 7. Cumulative Distribution of Waiting Time for First Access to the Final/Third Non-Working Hyperlink in the Presence of a Feedback Bar

\section{Conclusion and Future Research}

Although tolerable waiting time can vary under different circumstances and contexts, our study indicates that most users are willing to wait for only about two seconds for information retrieval tasks on the Web. Future research will need to assess the applicability of this finding to other tasks and contexts. Interestingly, in contrast to the general expectations, Selvidge (2003) found that Web delay time is not affected by task type (information retrieval, online purchasing, downloading a text file). Regardless, the effect of task nature (e.g., netsurfing, browsing, querying) on waiting time is one area that needs further research. To stimulate some ideas for future research, the following sections provide further discussions on the various variables that may affect Web users' tolerable waiting time.

\section{Nature of Task and Waiting Time}

Netsurfing refers to the scenario where users explore and wander around various websites without any clear objectives or purposes (Hayes, 1995). Compared to querying, browsing is a more casual search approach and is often practiced during activities such as exploratory learning. Querying refers to serious search with specific requirement and often involves a highly complicated search strategy such as the use of Boolean operators (i.e., AND/OR) in the queries. People who surf or browse the net are generally not willing to spend the same amount of time and resources as they would if they were querying for specific information (Reaux and Carroll, 1997). Hence, the nature of the task is expected to influence users' tolerance on download waiting time.

\section{Waiting Duration Information and Waiting Time}

Another interesting area for research is to study the effect of waiting duration information on tolerable waiting time. Providing users with waiting duration information is a common practice available on most Web browsers. For example, while a page is being downloaded, Netscape Navigator and Microsoft Explorer provide status or retrieval information on the bar located at the bottom of the browser window. The effect of this type of information, though believed to make long waiting time more tolerable, needs 
to be empirically studied and verified. For example, the study by Hui and Zhou (1996) shows that providing customers with waiting duration information does not reduce their perceived waiting duration, which is contrary to common beliefs. They also show that the status duration information increases tolerable waiting time not by changing customers' perception of the waiting duration but by increasing their perceived cognitive control (Folkman, 1984). Hence, the mediating effects of providing status duration information will also need to be investigated.

\section{Display Techniques and Waiting Time}

One technique that has been used to ease users' frustration when waiting for Web pages to appear is the interlacing technique. Using this technique, the image first appears as a vague image, and then slowly clears up and becomes more focused as more data is received. How does this technique compare to the usual top-down approach? Intuitively, one would expect the interlacing technique to be superior. Allan (1979), however, indicates that, "a filled interval is judged as longer than an empty interval of the same stimulus duration". If this finding also applies to Web access, then the interlacing technique would result in longer perceived waiting time. Empirical research is needed to compare the different strategies of displaying Web pages and their impact on waiting time.

\section{Implications for Practice and Research}

According to Zona Research (2001), "for every second of latency over normal expectations of that page, a Web transaction accumulates a demerit" (p.6). In the same report, the risk of losing revenue due to site abandonment was also discussed. Designers and operators of websites need to ensure that their sites can be accessed within a reasonable amount of time, i.e., within 2 seconds for every page, or they risk losing revenues. The 2 -second rule can also be used by network service providers and administrators to determine their hardware and software requirements and investments, and by Web designers to decide on the optimal design of websites.

In this research, the concept of perceived waiting time was not studied. Research has shown that there is a linear relationship between perceived time and actual time (Allan, 1979; Hornik, 1984; Rule, Curtis and Markley, 1970). In fact, Hornik (1984) found that individuals exhibit the tendency to overestimate waiting time. This is consistent with Cottle's (1976) findings where it was found that subjects have a tendency to overestimate passive durations (such as waiting) and underestimate active durations of time.

It is important to study perceived waiting time in future research because it directly influences a user's decision to either give up or continue waiting for the download of a Web page. In fact, perceived waiting time may be more relevant and important than true waiting time, as a user seldom bases his/her decision to continue or quit waiting by the actual length of time s/he has waited, but rather by the amount of time $\mathrm{s} / \mathrm{he}$ perceives s/he has waited. Consequently, different types of techniques can be used to reduce Web users' perceived waiting time, which may prolong users' actual waiting time. For example, Allan (1979) pointed out that perceived duration could be influenced by non-temporal characteristics such as modality, nature (filled vs. empty), energy, and complexity.

Given that long waiting time has always been one of the leading concerns for Web users (GVU, 1998; Lightner et al., 1996), it is important for researchers and practitioners to: 1) understand users' waiting behavior in accessing the Web, 2) propose and evaluate techniques to reduce users' perception of waiting time, and 3) recommend a trade-off between download/access time and aestheticism of Web pages. Finally, it is hoped that this research will stimulate the interest of other researchers to examine issues related to waiting time for different Web activities. Researchers and practitioners can contribute to this area of research by proposing mechanisms to either reduce users' waiting time or make their Web experience more pleasing or tolerable, as well as evaluating the effectiveness and impact of these mechanisms on users' perceptions and behavior.

\section{References}

Allan, L. G. "The perception of time," Perception and Psychophysics, 26(5), 1979, pp. 340-354.

Bailey, B. "Acceptable computer response times", UI Design Update Newsletter, April 2001. Available at: http:// www.humanfactors.com/downloads/apr012.htm\#bobbailey.

Chen, B. "The 30-second rule", Network World, July 22, 2002. Available at: http://www.nwfusion.com/columnists/2002/ 0722chen.html. 
Cottle, T.J. Perceiving Time: A Psychological Investigation with Men and Women, New York, John Wiley, 1976.

Dellaert, B.G.C. \& Kahn, B.E. "How tolerable is delay? Consumers' evaluations of Internet Web sites after waiting," Journal of Interactive Marketing, 13(1), 1999, pp. 41-54.

Folkman, S. "Personal control and stress and coping process: a theoretical analysis," Journal of Personality and Social Psychology, 46, 1984, pp. 839-852.

Fry, M. "How users perceive and respond to download times on the World Wide Web: a review of the literature", Drexel University, Working Paper, May 31, 2001. Available at: http://www.pages.drexel.edu/ mwf24/DownloadTime.doc.

Galletta, D., Henry, R., McCoy, S. \& Polak, P. "Web site delays: how slow can you go?" Presented at the First Annual Pre-ICIS Workshop on HCI Research in MIS, Barcelona, Spain, December 2002.

Graphics, Visualization \& Usability (GVU) Center. GVU's User Surveys. Georgia Tech Research Corporation, April 1995 to October 1998. Available at http://WWW.cc.gatech.edu/gvu/user_surveys/.

Hayes, M. "Working online or wasting time?" Information Week, May 1,1995 , pp. 38-51.

Hornik, J. "Subjective vs. objective time measures: a note on the perception of time in consumer behavior", Journal of Consumer Research, 11, June 1984, pp. 615-618.

Hoxmeier, J.A. \& DiCesare, C. "System response time and user satisfaction: an experimental study of browser-based applications," Proceedings of the Association of Information Systems Americas Conference, Long Beach, California. August 2000.

Hui, M. K. \& Zhou L. "How does waiting duration information influence customers' reactions to waiting for services?" Journal of Applied Social Psychology, 26(19), 1996, pp. 1702-1717.

Lightner, N. J., Bose, I., \& Salvendy, G. "What is wrong with the world-wide web? A diagnosis of some problems and prescription of some remedies," Ergonomics, 39(8), 1996, pp. 995-1004.

Miller, R.B. "Response time in man-computer conversational transaction," Proceedings of AFIPS Fall Joint Computer Conference, 33, 1968, pp. 267-277.

Nielsen, J. "Response times: the three important limits". Available at http://www.useit.com/papers/responsetime.html. Exxcerpt from Chapter 5 of Usability Engineering by Jakob Nielsen, Academic Press, 1993.

Nielsen, J. "Guidelines for multimedia on the web," Jakob Nielsen's Alertbox for December, 1995. Available at http://www.useit.com/alertbox/9512.html.

Nielsen, J. "Top ten mistakes in Web design," Jakob Nielsen's Alertbox for May, 1996. Available at http://www.useit.com/ alertbox/9605.html.

Nielsen, J. "The need for speed," Jakob Nielsen's Alertbox for March, 1997. Available at http://www.useit.com/alertbox/ 9703a.html.

Nielsen, J. "User interface directions for the web," Communications of the ACM, 42 (1), 1999, 65-72.

Pitkow, J.E. \& Kehoe, C.M. "Emerging trends in the WWW user population," Communications of the ACM, 39(6), 1996, pp. 106108.

Ramsay, J., Barbesi, A. \& Preece, J. “A psychological investigation of long retrieval times on the world wide web," Interacting with Computers, 10(1), 1998, pp. 77-86.

Reaux, R. A. \& Carroll, J. M. "Human factors in information access of distributed systems," in Salvendy, G. (Eds.), Handbook of Human Factors \& Ergonomics, $2^{\text {nd }}$ Ed., John Wiley \& Sons, Inc., NY, 1997.

Rule, S.J., Curtis, D.W., and Markley, R.P. "Input and output transformations from magnitude estimation", Journal of Experimental Psychology, 86 (1), 1970, pp. 343-349.

Selvidge, P. "How long is too long for a website to load?" Usability News, 1(2), 1999. Available at: http://psychology. wichita.edu/surl/usabilitynews/1s/time_delay.htm.

Selvidge, P. "Examining tolerance for online delays," Usability News, 5(1), 2003. Available at: http://wsupsy.psy.twsu.edu/ surl/usabilitynews/51/delaytime.htm.

Shneiderman, B. "Response time and display rate in human performance with computers," Computing Surveys, 16, 1984, pp. 265285.

Zona Research Report, “The Need for Speed”, July 1999.

Zona Research, "The Need for Speed II", Zona Market Bulletin, 5, April 2001. Available at: http://www.keynote.com/ downloads/Zona_Need_For_Speed.pdf. 